\title{
EDUCAÇÃO MULTI/INTERCULTURAL E O DIÁLOGO COM OS PROFESSORES SOBRE A DIFERENÇA NO CONTEXTO ESCOLAR
}

\author{
MULTI / INTERCULTURAL EDUCATION AND DIALOGUE WITH TEACHERS \\ ABOUT THE DIFFERENCE IN THE SCHOOL CONTEXT
}

Sara Moitinho 29

\begin{abstract}
Resumo
Este artigo apresenta análises e reflexões construídas com base nos resultados de uma pesquisa de mestrado defendida no programa de Pós-Graduação da PUC-Rio, cujo objetivo era conhecer e compreender como as professoras lidam com a diversidade cultural e étnicorracial que permeia o cotidiano escolar. Identificamos a percepção dos professores a partir dos depoimentos que produzimos no contexto onde a pesquisa foi realizada. A escolha do referencial teórico-metodológico baseou-se nos autores que trabalham com a educação multi/intercultural, com as questões relativas à diversidade cultural, às diferenças e às relações raciais no cotidiano escolar. A metodologia esteve pautada na abordagem qualitativa de pesquisa de cunho etnográfico. Os relatos coletados demonstram que as professoras reconhecem as situações da diversidade étnicorracial no contexto da escola, mas ao mesmo tempo, ainda não sabem lidar com esta situação, e acabam focando a questão no social. Ou seja, os problemas relacionados às questões de raça na escola, são reduzidos aos problemas sociais.
\end{abstract}

Palavras-chave: Diferença. Diversidade cultural. Educação multi/interculturalidade.

\begin{abstract}
This article presents analyzes and reflections that are constructed bases on the results of a master's research that was defended on the PUC RIO graduate program, whose objective was get to known and understand as well, how teachers handle the cultural and ethnic-racial diversity that is part of the school routine. We identified the perception of the teachers by the testimonies we produced, in the context where the research was carried out. The choice of the theorical-methodological reference was based on authors that works with multi and intercultural education, and also with issues that are related

\footnotetext{
${ }^{29}$ Mestre e Doutora em Educação pela Universidade de São Paulo - USP. É professora do Mestrado Profissional Bilíngue do Instituto Nacional de Educação de Surdos (INES) e, também, professora do Curso de Pedagogia, atuando nas disciplinas de Didática e Estágio Supervisionado. Tem se dedicado aos estudos da educação de surdos, saberes de alunos surdos no Curso de Pedagogia Bilíngue do INES e também à temática da Educação Bilíngue e Intercultural , mas com o olhar para a Educação em Direitos Humanos em uma perspectiva intercultural Bilíngue. E-mail: saramoitinho@hotmail.com saramoitinho@ines.gov.br e Telefone:(21) 98298-2725 ORCID https://orcid.org/0000-0002-2625-3925
} 


\section{RevistAleph}

to cultural diversity, differences, and racial relations in the school life. The methodology was based on the qualitative perspective of a geographic ethnicity research. The collected results demonstrates that the teachers are able to recognize the situations of ethnic-racial diversity in the schools, but on the other hand, they still do not know how to deal whit this situation, and ended up focusing on the social issue. In another words, problems that are related to race issues, are being reduced to social problems at schools.

Keywords: Difference. Cultural diversity. Multi / intercultural education.

\section{Introdução}

Este trabalho é fruto de uma dissertação de mestrado defendida na Pontifícia Universidade Católica do Rio de Janeiro e teve como objetivo entender como as professoras lidam com a diversidade sociocultural e a étnicorracial no contexto escolar. A questão central que orientou a pesquisa foi buscar entender como a escola vivencia as relações étnicorraciais no cotidiano escolar a partir das "vozes" das professoras sobre as crianças negras no cotidiano da escola pesquisada e será dedicado à análise do material das entrevistadas realizadas com as professoras, diretora, coordenadora e funcionários sobre as crianças.

\section{Educação, multiculturalismo e a perspectiva intercultural}

Parto da afirmação de que as questões multiculturais apresentam especificidades nos diferentes contextos, considerei importante abordar as contribuições de autores de diversas procedências.

Apresentarei sinteticamente alguns desses autores que trabalham com as questões referentes ao multiculturalismo e à perspectiva intercultural no cotidiano escolar. Começarei pelo canadense radicado nos Estados Unidos Peter McLaren (1997, 2000) e pelo autor francês Jean-Claude Forquin (1993). Abordarei também autores que 


\section{RevistAleph}

estudam a perspectiva multicultural e intercultural no contexto brasileiro, como Vera Maria Candau (2002, 2005, 2006) e Reinaldo Matias Fleury $(2003,2006)$.

Peter McLaren (2000) é professor e atualmente membro do corpo docente do Curso de Pós-Graduação em Estudos de Educação e Informação da Universidade da Califórnia nos Estados Unidos. Possui uma vasta experiência em diversas escolas públicas da periferia, e é um dos principais representantes da pedagogia crítica. Analisa o multiculturalismo como projeto político e enumera quatro principais tendências dentro desta abordagem. Ao propô-las reconhece que, na prática, essas tendências tendem a se inter-relacionar.

Apresentarei a seguir as quatro tendências do multiculturalismo identificadas por McLaren (2000):

- Multiculturalismo conservador - essa posição defende a hierarquização dos diferentes grupos étnico-raciais, a superioridade branca, o projeto de uma cultura comum de base ocidental e eurocêntrica, deslegitima outras formas de conhecer e aprender, saberes, línguas, crenças e valores diferentes, pertencentes aos grupos subordinados. Nesta concepção, "os multiculturalistas conservadores disfarçam falsamente a igualdade cognitiva de todas as raças e acusam as minorias mal sucedidas de terem "bagagens culturais inferiores" e a "carência de fortes valores de orientação familiar" (MCLAREN, 2000, p. 113). Nesta visão, as contribuições dos grupos étnicos são reduzidas a "acréscimos" à cultura dominante, que tem por base os padrões que se baseiam no capital cultural da classe média. McLaren afirma que esta é uma posição que deve ser contestada, pois utiliza o termo diversidade para encobrir seu caráter assimilacionista e hierarquizador.

- Multiculturalismo humanista liberal - afirma uma igualdade intelectual entre as diferentes etnias e grupos sociais, o que garantiria a todos competirem em uma sociedade capitalista. No entanto, para que esta seja possível é necessário promover uma igualdade de oportunidades. As desigualdades seriam produzidas pelas diferentes capacidades e empenho dos indivíduos. Esta posição acredita que as restrições econômicas e socioculturais existentes podem ser transformadas e modificadas com o objetivo de se alcançar uma igualdade de oportunidades entre os diferentes grupos para que todos possam competir na sociedade. Esta visão, ao afirmar a igualdade existente entre os grupos, sem questionar as relações sociais de poder, acaba fortalecendo o grupo social dominante. Propõe políticas de caráter compensatório orientadas a que grupos 


\section{RevistAleph}

minoritários possam alcançar a cultura comum de caráter eurocêntrico ou ocidental e branca.

Para McLaren (2000, p. 119 e 120):

Esta visão resulta frequentemente em um humanismo etnocêntrico e opressivamente universalista no qual as normas legitimadoras que governam a substância da cidadania são identificadas mais fortemente com as comunidades político-culturais anglo-americanas.

- A terceira, multiculturalismo liberal de esquerda, enfatiza a diferença cultural e afirma que privilegiar a igualdade entre as raças/etnias pode abafar diferenças culturais importantes entre elas, as quais são responsáveis por valores, atitudes, estilos cognitivos e práticas sociais diferenciadas. Segundo McLaren, essa posição pode tender a essencializar as diferenças culturais e, portanto, tende a ignorar a construção histórica e cultural da diferença, "pois o multiculturalismo liberal de esquerda trata a diferença como uma essência que existe independentemente de história, cultura e poder" (MCLAREN, 2000, p.120). Segundo o autor, acaba ocorrendo um certo elitismo populista que valoriza as experiências dos grupos populares e étnicos e praticamente não leva em consideração a cultura dominante.

- $E$, por último, o multiculturalismo crítico ou de resistência que entende as representações de classe, gênero e raça como produtos de lutas sociais sobre signos e significados. Enfatiza a tarefa central de transformar as relações sociais, culturais e institucionais nas quais os significados são gerados. McLaren (2000) afirma que o multiculturalismo de resistência também se recusa a ver a cultura como não-conflitiva, harmoniosa e consensual. O multiculturalismo de resistência argumenta que a diversidade deve ser afirmada dentro de uma política de crítica e comprometida com a justiça social, posição que o autor defende e com a qual se identifica. Para o autor, "o multiculturalismo crítico tem de estar atento à noção de diferença". Diferença é sempre um produto da história, cultura, poder e ideologia. A diferença ocorre entre dois grupos e entre muitos grupos e deve ser compreendida em termos das especificidades de sua produção (MCLAREN, 2000, p. 123-124).

Nesta perspectiva Mclaren (2000, p. 150) afirma:

O projeto que sustenta uma educação multicultural necessita estar situado a partir do ponto de vista não apenas do outro concreto, mas também do outro generalizado. Todos os direitos universais nesta visão devem reconhecer as necessidades e desejos específicos do 


\section{RevistAleph}

outro concreto sem sacrificar o ponto de vista do outro generalizado, sem o qual torna-se completamente impossível falar de uma ética radical. (...) Justiça social é um objetivo que precisa ser situado histórica, contextual e contingentemente como o produto de lutas materiais sobre os modos de inteligibilidade, bem como de práticas institucionais e sociais.

O autor propõe que é preciso assumir a questão da diferença e "criar uma política de construção de alianças, de sonhos compartilhados, de solidariedade que avance para além de posturas condescendentes (como, por exemplo, 'a semana das raças', que na verdade servem para manter as formas de racismo institucionalizado intactas" (MCLAREN., 1997, p. 95).

Segundo McLaren, a tensão entre múltiplas etnicidades e a política da justiça universal é a questão urgente do atual milênio.

Outra contribuição fundamental de McLaren é a afirmação de se considerar a sala de aula como um espaço de narrativas no plural, para que a narrativa única, alicerçada na crença dos conhecimentos universais, seja problematizada. Só assim, se desafiará a branquidade e o eurocentrismo, pois será preciso abrir espaços para as múltiplas narrativas, sejam elas contra- hegemônicas ou não.

Para o autor, a questão central para os educadores críticos é desenvolver um currículo e uma pedagogia multicultural que se preocupem com a especificidade "em termos de raça, classe, gênero, orientação sexual etc. da diferença" (MCLAREN,1997, p. 70).

Neste sentido, McLaren (1997, p. 195-200) afirma que:

A pedagogia crítica tenta oferecer aos professores e pesquisadores um meio de melhor entender o papel que as escolas de fato representam dentro de uma sociedade dividida em raça, classe e gênero; e, neste esforço, os teóricos produziram categorias ou conceitos para questionar as experiências de estudantes, textos, ideologias de professores e aspectos do método escolar, que as análises conservadoras e liberais deixam com frequência inexplorados. (...) A natureza dialética da teoria crítica permite ao pesquisador em educação ver a escola simplesmente como uma arena de doutrinação ou socialização ou um local de 


\section{RevistAleph}

instrução, mas também como um terreno cultural que confere poder ao estudante e promove a autotransformação.

A sala de aula, para McLaren, é, portanto, um local de socialização, de encontro, um espaço de múltiplas narrativas de construção, transformação e empoderamento, não podendo ser reduzida a um espaço exclusivamente de instrução. Certamente esta é uma das grandes contribuições da pedagogia crítica por ele proposta.

A educação multicultural na perspectiva da pedagogia crítica opõe-se veementemente à persistência das desigualdades de raça, gênero e classe. E para isto é necessário "desenvolver uma práxis dialética que permita fazer uma relação entre a vida cotidiana e esses processos de globalização. Também devem ser capazes de auxiliar os alunos a ver essa dialética e tornar-se pesquisadores desse cotidiano" (MCLAREN, 2004, p. 2).

McLaren afirma que será preciso usar as experiências de vida dos alunos e da comunidade como base do currículo. Nesta perspectiva, o educador precisa politizar suas aulas questionando a imposição da cultura hegemônica centrada no mercado, para que, além de aprender a ler e a escrever, os alunos possam compreender a realidade em que vivem. A arte da pedagogia crítica é criar um espaço onde cada um possa manifestar a sua opinião e desafiar a do interlocutor sem a silenciar, mesmo que os argumentos explicitados sejam muito diferentes dos próprios.

As considerações de Peter McLaren foram fundamentais para compreender as tensões entre desigualdade e diferença. Para o autor, os sistemas de diferença existentes que organizam a vida social em padrões de dominação e subordinação devem ser reconstruídos. No livro "Multiculturalismo Crítico" (Mclaren, 2000), ele convida educadoras e educadores críticos para uma "reescrita da diferença como diferença - em - relação" (Mclaren, 2000, p. 134), para que possamos lutar pelas mudanças dramáticas das "condições materiais que permitem que as relações de dominação prevaleçam sobre as relações de igualdade e justiça social” (MCLAREN, 2000, p. 134). 


\section{RevistAleph}

McLaren (2001) apresenta algumas posições e ações necessárias aos educadores críticos:

- relacionar os processos de grupo que ocorrem dentro de sua sala de aula com a configuração capitalista de nossa sociedade;

- desenvolver uma práxis que permita fazer uma relação entre a vida cotidiana e os processos de globalização;

- orientar os alunos a ver essa dialética e tornarem-se pesquisadores desse cotidiano, de modo a ajudá-los a desenvolver um senso de responsabilidade pelos seus desejos, sonhos e ações. Será preciso usar as experiências de vida de nossos alunos e da comunidade como base do currículo.

Assim, este autor é de suma importância, na medida em que apresenta propostas para se pensar em uma prática multiculturalmente orientada a partir de uma pedagogia crítica que busque o empoderamento tanto dos/as alunos/as quanto dos professores/as.

Segundo a professora Vera Maria Candau (2005), temos que estar cientes de que existem diversos modos de entender o multiculturalismo, vários modelos de educação multicultural, assim como é importante que tenhamos consciência de que lidamos com diferentes conceitos de cultura e que esses conceitos precisam ser permanentemente definidos e explicitados em nossas pesquisas. Assim, o multiculturalismo é ao mesmo tempo um dado da realidade, pois vivemos em sociedades multiculturais e precisamos entender essa realidade, é uma maneira de situar-nos em relação a este contexto e intervir nele através de práticas sociopolíticas, culturais e educacionais.

Para Candau (2006) em sintonia com Forquin, a perspectiva intercultural se situa no âmbito mais amplo da abordagem multicultural. Trata-se de um enfoque que afeta a educação em todas as suas dimensões, favorecendo uma dinâmica crítica e autocrítica, procurando valorizar a interação e a comunicação recíprocas entre os diferentes sujeitos e grupos culturais. 


\section{RevistAleph}

Para que possamos entender a perspectiva intercultural no contexto escolar, precisamos aprofundar no que ela significa e qual a contribuição dessa perspectiva para se pensar em uma educação que trabalhe com a diversidade étnico-racial e cultural no cotidiano escolar. Desse modo, cabe perguntar: quais seriam, então, os critérios básicos para se promover processos educativos em uma perspectiva intercultural. Candau (2005) enumera alguns que considera fundamentais:

- entender a educação como uma prática social em íntima relação com as diferentes dinâmicas presentes em cada sociedade concreta;

- articular as políticas educativas, assim como as práticas pedagógicas, procurando reconhecer e valorizar a diversidade cultural, além de ter presente as questões relativas à igualdade e ao direito à educação como direito de todos/as;

- a educação intercultural não pode ser reduzida a algumas situações e/ou momentos específicos ou a determinadas áreas curriculares, nem focalizar as atividades exclusivamente em referência a determinados grupos sociais. Busca um enfoque global que deve afetar a cultura escolar e a cultura da escola como um todo, e todos os atores e dimensões do processo educativo;

- questiona o etnocentrismo que, explícita ou implicitamente, está presente na escola e nas políticas educativas e coloca uma questão fundamental: que critérios utilizar para selecionar e justificar os conteúdos - em sentido amplo - da educação escolar?

- a educação intercultural afeta não somente o currículo explícito, como também o currículo oculto e as relações entre os diferentes sujeitos no processo educativo.

A educação intercultural, assim concebida "orienta processos que têm por base o reconhecimento do direito à diferença e a luta contra todas as formas de discriminação e desigualdade social" (CANDAU, 2002, p. 102).

Para a autora, educar na perspectiva intercultural implica, portanto, uma clara e objetiva intenção de promover o diálogo e a troca entre os diferentes grupos sociais, culturais e étnicos. Assim, Candau (2005) enumera alguns desafios para se trabalhar com a educação intercultural na perspectiva crítica. São eles: 


\section{RevistAleph}

- Desconstruir: para a promoção de uma educação intercultural, é necessário reconhecer o caráter desigual, discriminador e racista da sociedade brasileira, procurando questionar o caráter monocultural e o etnocentrismo que, explícita ou implicitamente, estão presentes na escola, nas políticas educativas e nos currículos escolares.

- Articular igualdade e diferença: é importante articulá-las no nível das políticas educativas, assim como das práticas pedagógicas, reconhecer e valorizar a diversidade cultural e a igualdade de direitos.

- Resgatar os processos de construção das nossas identidades culturais, tanto no nível pessoal como no coletivo.

- Promover experiências de interação sistemática com os "outros". Reconstruir a dinâmica educacional: não se pode reduzir a educação intercultural a algumas situações e/ ou atividades realizadas em momentos específicos, mas esta deve afetar a todos os atores e a todas as dimensões educativas. É necessário também favorecer processos de "empoderamento", principalmente de grupos sociais que foram historicamente excluídos da sociedade.

Nesta perspectiva, a partir dos desafios que a autora apresenta, podemos constatar que a educação pautada na perspectiva intercultural tem como público privilegiado grupos que foram historicamente excluídos do sistema educacional e social, e visa a reconstrução de práticas pedagógicas baseadas no reconhecimento de diferentes conhecimentos e da valorização da diversidade étnico-cultural e social, pois,

educar na perspectiva da interculturalidade implica, portanto, uma clara e objetiva intenção de promover o diálogo e a troca entre os diferentes grupos e indivíduos que os constituem abertos e em permanente movimento de construção, decorrente dos intensos processos de hibridização cultural (CANDAU e KOFF, 2006, p. 102). 


\section{RevistAleph}

Ao tratar das questões da perspectiva intercultural no cotidiano escolar e as questões da diversidade étnico-racial, estou levantando questões para a construção de uma educação que aposta na relação entre os diferentes grupos sociais e étnicos. Assim, a perspectiva intercultural busca a promoção de uma educação pautada na valorização do outro e das diferentes práticas socioculturais, na interrelação com os diferentes grupos em busca da construção de uma sociedade justa e mais humana, onde se possa articular diferentes políticas de igualdade e de identidade, na perspectiva da construção democrática.

As contribuições de Candau foram fundamentais para entendermos a perspectiva intercultural no cotidiano escolar. Uma educação que busca favorecer a construção de um projeto comum, no qual as diferenças sejam reconhecidas e integradas dialeticamente.

Outro autor em que me apoiei para pensar a perspectiva intercultural na educação foi Reinaldo Matias Fleury $(2003,2006,2008)$, atualmente professor titular do Centro de Educação da Universidade Federal de Santa Catarina (UFSC). Fleury afirma que nos últimos anos vários autores e autoras vêm discutindo os significados, possibilidades e impasses do que está sendo denominado educação intercultural. Assinala que há grande diversidade de termos e concepções sendo utilizados para refere-se à relação e ao respeito entre os grupos socioculturais. Para o autor o termo multicultural tem sido utilizado como categoria descritiva, analítica, sociológica ou histórica. Afirma que, à medida que foi ampliando e aprofundando seus estudos, foi dialogando sucessivamente com diferentes concepções de educação multicultural e intercultural. Mas, hoje, entende o multiculturalismo como indicador da realidade de coexistência de diversos grupos culturais na mesma sociedade, enquanto o termo interculturalidade serve para indicar o conjunto de propostas de convivência e de relação democrática e criativa entre culturas diferentes (FLEURY, 2006, p. 14)

Segundo Fleury, a intercultura seria 


\section{RevistAleph}

este complexo campo de debate em que se enfrentam polissemicamente (constituindo diferentes significados, a partir de diferentes contextos teóricos e políticos, sociais e culturais) e polifonicamente (expressando-se através de múltiplos termos e concepções, por vezes ambivalentes e paradoxais) os desafios que surgem nas relações entre diferentes sujeitos socioculturais (FLEURY, 2006, p. 15).

Nesse enfoque, a perspectiva intercultural deixa de ser assumida como um processo de formação de conceitos, valores, atitudes a partir de um único direcionamento, unidimensional e unifocal. Passa a ser entendida como o processo construído pela relação tensa e intensa entre os diferentes sujeitos, criando contextos em relação aos quais os diferentes sujeitos desenvolvem suas respectivas identidades (FLEURY, 2004).

Para o autor, a educação intercultural busca a possibilidade de respeitar as diferenças e de integrá-las em uma interação que não as anule, mas que ative o potencial criativo e vital da conexão entre diferentes agentes e entre seus respectivos contextos.

Fleury, em um artigo publicado em 2003 no periódico Revista Brasileira de Educação, ao abordar a Educação Intercultural afirma que o "trabalho intercultural pretende contribuir para superar tanto a atitude de medo quanto a de indiferente tolerância ante o "outro", construindo uma disponibilidade para a leitura positiva da pluralidade social e cultural" ( p. 17)

Segundo o autor:

A educação intercultural assumiu a finalidade de promover a integração entre culturas, a superação de velhos e novos racismos, o acolhimento dos estrangeiros e, particularmente, dos filhos dos imigrantes na escola. (...) Nessa perspectiva, a intercultura vem se configurando como um objeto de estudo interdisciplinar e transversal, no sentido de tematizar e teorizar a complexidade. (...) O objeto de nosso estudo, assim, constitui-se transversalmente às temáticas de 


\section{RevistAleph}

cultura, de etnia, de gerações e de movimento social (FLEURY, 2003, p. 23).

Azibeiro e Fleury (2008) afirmam que nesta perspectiva a educação intercultural passa a ser entendida como um processo de construção na relação entre os diferentes sujeitos, procurando criar contextos nos quais os diferentes sujeitos desenvolvem suas respectivas identidades, criando contextos interativos, criativos e propriamente formativos. Desse modo, pensar na educação intercultural supõe a perspectiva que "pode tornar-se possível a dissolução de preconceitos e estereótipos e a produção de processos de subjetivação e constituição de identidades dessubalternizadas (AZIBEIRO e FLEURY, 2008, p. 16).

Neste artigo assumo a opção por uma perspectiva intercultural da multiculturalidade, em sintonia com o multiculturalismo crítico de McLaren, e com a posição de Candau (2008) e Fleury (2006). Nesse sentido, a interculturalidade supõe a

relação entre diferentes grupos sociais e culturais, com base na concepção do "reconhecimento do direito à diversidade e na luta contra todas as formas de discriminação e desigualdade social e tenta promover relações dialógicas e igualitárias entre pessoas e grupos que pertencem a universos culturais diferentes" (CANDAU, 2008, p. 47) .

\section{Reflexões metodológicas: a coleta de dados}

Quanto à metodologia utilizada na pesquisa empírica, a opção foi privilegiar um estudo de caso de inspiração etnográfica, pois, como afirma Sarmento (2003), a etnografia tem como função apreender a vida tal como ela é diariamente conduzida, simbolizada e interpretada, de acordo com os atores sociais nos seus contextos de ação. A vida é plural nas suas manifestações, imprevisível e ambígua nos seus significados. Procurei então mergulhar no cotidiano escolar para compreender, a partir das experiências das professoras, seus modos de ser, viver e relacionar-se com colegas e 


\section{RevistAleph}

professores/as. Para tal, foram realizadas observações pelo período de cinco meses, com uma carga horária de vinte horas de observação por semana, durante quatro vezes na semana, em uma sala de aula do primeiro ano do Ensino Fundamental. Embora tenha sido privilegiada a sala de aula, também outros espaços, como recreio, refeitório, corredores, entrada e saída das crianças, além da sala das professoras, foram locais observados. Após a observação foram realizadas cinco entrevistas semi-estruturadas com três professoras, uma coordenadora e a diretora adjunta da escola.

Marli André (2007) afirma que o pesquisador não deve se limitar à descrição das situações, mas

deve ir muito além a tentar reconstruir as ações e interações dos atores sociais segundo seus pontos de vista, suas categorias de pensamento, sua lógica. Na busca das significações do outro, o investigador deve, pois, ultrapassar seus métodos e valores, admitindo outras lógicas do entender, conceber e recriar o mundo. A observação participante e as entrevistas profundas são, assim, os meios mais eficazes para que o pesquisador aproxime-se dos sistemas de representação, classificação e organização do universo estudado (ANDRÉ, 2007, p. 45).

Foram realizadas cinco entrevistas. A escolha dos profissionais entrevistados considerou critérios como a função exercida, a disponibilidade de tempo, o foco da pesquisa, além da possibilidade de privilegiar um professor de cada série, buscando-se um amplo conhecimento da escola que estava sendo investigada.

As entrevistas semiestruturadas foram realizadas após a conclusão da observação participante, permitindo uma maior abertura para aprofundar e compreender a realidade que estava sendo estudada, pois já havia uma relação construída entre as entrevistadas e a pesquisadora.

As entrevistas foram realizadas com a diretora adjunta da escola, com a coordenadora educacional e com três professoras das séries iniciais do Ensino Fundamental: uma professora do primeiro ano, uma do segundo e outra do quarto. 


\section{RevistAleph}

Quase todas as professoras entrevistadas têm uma ampla experiência no magistério, com um tempo de serviço de quase 20 anos em sala de aula. A diretora adjunta e a professora do quarto ano são formadas em Pedagogia, com especialização em supervisão e administração escolar.

As entrevistas foram realizadas no ambiente escolar, mais especificamente, na sala de cada entrevistada. A entrevista com a diretora adjunta foi realizada na sala principal da direção e a diretora geral estava presente durante sua realização.

O roteiro das entrevistas foi construído de acordo com as questões centrais da pesquisa, além das questões que emergiram a partir das observações participantes. 0 roteiro foi o mesmo para todas as entrevistas, com algumas modificações, visando uma maior adequação à especificidade de cada entrevistado.

As entrevistas foram estruturadas da seguinte maneira: no primeiro momento, foi solicitada uma pequena apresentação minha para a professora que estava sendo entrevistada; ela respondeu um breve questionário com três tópicos: dados pessoais (nome, idade, cor e religião); formação acadêmico-profissional e participação em movimentos, organizações, sindicatos, grupos comunitários. O segundo momento da entrevista foi desenvolvido tendo por base treze perguntas abordando os seguintes aspectos: trajetória profissional e seus maiores desafios; tempo de serviço na escola; caracterização da clientela da escola; suas diferentes características raciais, sociais, religiosas, de gênero etc; as tensões ou dificuldades que enfrenta na escola; como são os relacionamentos das crianças entre si e com os adultos; presença de conflitos, preconceitos, e discriminação no cotidiano escolar; como a escola lida com as crianças negras e moradoras de favelas; contribuições dos cursos de formação para a prática pedagógica. Lembro que durante minhas observações e conversas informais travadas nas salas de aula, procurei focalizar esses mesmos aspectos. 


\section{RevistAleph}

\section{Tecendo relações entre os depoimentos das professoras $\mathrm{e}$ as relações multi/interculturais}

Este item tem como objetivo apresentar os depoimentos das professoras, diretoras e coordenadoras sobre as questões que nortearam esta pesquisa. As vozes destes profissionais foram fundamentais, pois convivem direta e cotidianamente com as crianças.

\section{Os principais desafios declarados pelas professoras}

O nosso principal desafio aqui na escola é a violência.

Quando você tem uma turma de $4 \underline{a}$ série, com dificuldades de leitura e escrita, pois todos são repetentes, com problemas sociais e econômicos, o que fazer?

Como encontrar soluções para essas diferenças na sala de aula? Quais as atividades que eu posso utilizar para ajudá-los?

Temos uma realidade injusta na sala de aula e não é só a dificuldade com a leitura e escrita, mas um desafio maior, que neste momento, é a violência.

Nós temos dificuldade para trabalhar com esta realidade de alunos inseridos em contextos com facções antagônicas e violentas e também para trabalhar com esta diversidade na sala de aula.

Acima estão expressas as falas das professoras entrevistadas em relação aos desafios que enfrentam no cotidiano escolar.

Em relação aos mesmos, todas comentaram sobre a complexidade da educação na nossa sociedade, seja em relação às diferenças de aprendizagem, à desigualdade social, aos alunos "carentes", ou seja, de classes populares, à ausência da família e à questão da violência que as crianças da escola pesquisada tinham que enfrentar, pois eram de contextos extremamente violentos. Segundo as entrevistadas, este é um desafio especialmente forte para a escola, hoje, que traz consequências para o processo educativo. 


\section{RevistAleph}

Outro desafio para a escola, de acordo com os depoimentos das professoras entrevistadas, é a dificuldade em lidar com a diferença e diversidade na escola, como afirma uma das professoras:

É muito difícil lidar com a diferença e a diversidade na escola, temos que aprender muita coisa. Nós só nos preparamos para receber um grupo específico e hoje lidamos com essa diversidade aqui na escola, na sala de aula, e temos que aprender e encará-la porque a diferença está dentro da escola (Professora Bia).

A diferença e a diversidade estão presentes na escola pesquisada, mas nas falas das professoras também está presente a dificuldade em lidar com elas. Trechos de depoimentos que colhi são bons exemplos para apoiar tal interpretação.

Nós fomos preparadas para receber um grupo específico e hoje lidamos com essa diversidade aqui na escola". Aqui na escola $80 \%$ são alunos moradores de favelas e em sua maioria negra (Professor Jose).

O sistema abriu vagas nas escolas, deu acesso para todos, mas não garantiu a permanência dos alunos. Para garantir a permanência, criou-se bolsa escola, bolsa família, vale gás e mais outras coisas, mas e agora? E o direito à aprendizagem? O que vão fazer para garantir esse direito? Eu me sinto impotente diante dessas situações (Professora Carmen).

Os alunos são diferentes, a metodologia deveria ser voltada para esses alunos, só que nós temos uma metodologia antiga, não temos recurso para atender o aluno com dificuldades, com problemas comportamentais. Nós queremos usar métodos antigos com alunos novos. Então, o que acontece? Há um desinteresse do aluno, há uma desmotivação do professor, há uma desvalorização do profissional porque o poder público não olha para o professor. (...) Não é interessante que as pessoas sejam pensantes, que sejam críticas porque vão incomodar a sociedade, não é? Então, finge-se muitas vezes, que se ensina e o aluno finge que aprende. Eu não acredito nisso. Estou falando da realidade. Eu tento reverter esse quadro. Eu tento trabalhar com alunos de forma que eles sejam críticos, que se valorizem e o que se imagina é que a escola pública não deva ter qualidade... Mas, dentro do possível eu tento 


\title{
RevistAleph
}

trabalhar com metodologias dentro da realidade... motivando o aluno para que ele possa conseguir (Professora Juliana).

Fleury (2003) afirma que o tema da diferença e da identidade sociocultural é de especial importância para a escola hoje, no sentido da valorização das políticas afirmativas das minorias étnicas, de modo que as relações raciais ou as diferenças na educação promovam uma convivência democrática entre os diferentes grupos e culturas. "Trata-se do desafio de se respeitar as diferenças e de integrá-las em uma unidade que não as anule, mas que ative o potencial criativo e vital da conexão entre diferentes agentes e entre seus respectivos contextos." (p. 497).

Educar para a pluralidade é fazer das diferenças um caminho para ajudar a construir pistas para o avanço da construção de práticas pedagógicas comprometidas com as crianças negras e das camadas populares.

\section{As crianças que frequentam a escola}

\begin{abstract}
São crianças carentes - carência afetiva e econômica. Em sua maioria é composta por crianças negras e moradoras de favelas. Mas na escola pública sempre foi esse público de crianças das classes populares, em sua maioria, crianças negras. Eu vou fazer 25 anos de serviço e sempre trabalhei com esse público (Professora Bia).
\end{abstract}

São crianças provenientes das classes populares e moradoras de favelas. Inseridos em contextos violentos e com facções antagônicas. São crianças carentes - carência afetiva e financeira, e a gente procura trabalhar com elas sobre os valores: o amor ao próximo, respeito e solidariedade (Professora Josy).

As respostas foram quase todas as mesmas, pois as crianças que frequentam a escola, segundo os depoimentos das professoras, são alunos "carentes" e moradores de favelas. Afirmam que, em geral, sempre são alunos que não têm assistência da família, pois os pais trabalham e não têm tempo de dar assistência aos filhos. As professoras reconhecem que quem frequenta a escola são os alunos negros, moradores de favelas, 


\section{RevistAleph}

das classes populares. São meninos e meninas que chegam à escola com suas vidas e histórias já marcadas por processos de silenciamento, homogeneização e exclusão. MCLAREN (2004, p. 181) afirma que "crianças em desvantagem econômica são criadas pela sociedade para falhar já em tenra idade, destinadas a perpetuar o odioso ciclo sem fim da pobreza criada por uma cultura obcecada com sucesso e riqueza".

A seguir, apresento outros depoimentos das professoras que evidenciam como estas profissionais veem as crianças com as quais lidam no cotidiano escolar:

São crianças bastante carentes, não têm acompanhamento dos pais. Crianças que precisam de atenção, pois não têm atenção nenhuma dos pais, infelizmente. $O$ tempo que a gente passa com eles, quatro horas, é pouco pra suprir essa carência. Eu procuro estar em contato com os responsáveis para falar dos problemas das crianças e pedir que eles nos ajudem para que a gente possa trabalhar em parceria. Muitas vezes a gente não tem retorno, porque é uma vida sacrificada que esses pais levam (Professora Josy).

Eles são muito agressivos. São muito agressivos entre si (Professora, Bia).

Eu vou falar visando uma colega minha que fala, eu até questiono um pouco, que a escola pública é destinada a mais moradores de favela e uma grande maioria negros... Discordo..., Discordo. Mas, aqui na escola, a grande maioria é de negros e da favela. Apesar de que, aqui, temos alunos que moram em prédios, mas a maioria dessa escola é da favela. Mas eu digo que a maioria é de alunos carentes, eu vejo como alunos carentes, independente de morar na favela ou não, eu os vejo como alunos carentes (Professora Juliana).

Eles são crus. Eles não sabem nada. Parece que agora que eles estão compreendendo que estão na primeira série e estão estudando. Eles parecem meninos de pré-primário. Tem criança que não sabe nem pegar no caderno e no lápis, não tem coordenação motora. Eles não sabem nada. Temos que ensinar tudo, até noções de higiene, eles não têm... O pai não vem na escola. Você manda recado várias vezes e parece que não tem família (Professora Bia). 


\section{RevistAleph}

A política da universalização da educação básica convoca todos para os bancos escolares, mas esta mesma política não "mexe na matriz da sociedade, procura-se assimilar os grupos marginalizados e discriminados aos valores, mentalidades, conhecimentos socialmente valorizados pela cultura hegemônica" (CANDAU, 2008, p. 50). Nessa direção, apresento um trecho do caderno de campo que confirma essa interpretação:

Estamos no mês de maio e a professora da sala fez um cartaz para o dia das mães. Neste cartaz, a professora desenhou uma mãe negra com uma criança negra e outra branca ressaltando a diversidade da sala de aula e da escola. Caroline e Carol são meninas negras e têm 9 anos. Elas estão sentadas no fundo da sala, próximas do mural. Neste mural está o cartaz para o Dia das Mães. Caroline e Carol conversam sobre o cartaz e o texto que a professora fez. Carol passou o dedo no desenho da mãe negra com seu filho negro. Caroline admira o desenho feito pela professora, pois o desenho retrata a família delas. Na entrada da escola, a coordenação fez um mural para as mães, mas não são as mães da escola, pois a mãe que está sendo representada neste mural é uma mãe branca com seu filho branco no colo. As mães da escola pesquisada são negras, mulatas e mestiças. Essa não foi a primeira vez que observei, anotei e registrei crianças conversando sobre esse cartaz feito pela professora na sala de aula. Já presenciei várias crianças conversando em grupinhos sobre esse cartaz; já presenciei várias crianças alisando o desenho da mãe negra com seu filho negro. 0 mural da entrada da escola está muito bem feito, eles colocaram um plástico de proteção para que não fosse danificado. Ele está intacto, lindo e sem nenhuma perfuração ou rasura. O cartaz da sala de aula teve que ser retirado ontem, pois já estava todo sujo, amassado e descolando do mural. Perguntei para a professora sobre o cartaz e ela disse que tirou porque já está fazendo um novo, para o mês de junho. "Vou fazer um sobre festa junina". Ao contrário do cartaz da sala, onde sempre havia crianças passando a mão, lendo a mensagem ou olhando o desenho que estava retratando a sua família, nunca presenciei uma pessoa lendo ou conversando sobre o mural da entrada. As mães que estão ali representadas não são as mães da escola (Caderno de Campo).

Em entrevista, uma das professoras afirma: 


\section{RevistAleph}

Porque geralmente as pessoas colocam nos cartazes ou murais mães branquinhas, bonitinhas com crianças brancas...Se não me engano na entrada da escola o mural é enfeitado com mães brancas e seus filhos brancos. Então, assim como os cartazes podem ser de crianças brancas, também podem ser de crianças negras. Eu fiz para chamar atenção mesmo das crianças, porque existem as mães negras, crianças negras. E não só as mães brancas são bonitas. As mães negras também são bonitas (Professora Ângela).

Considero importante ressaltar o depoimento dessa professora, pois pensar a escola como um lócus marcado pela diferença é destacar as contribuições da perspectiva intercultural e multicultural na educação, buscando "promover uma educação para o reconhecimento do outro" (CANDAU, 2008), uma educação para a valorização das crianças negras como sujeitos de direitos, para o diálogo entre os diferentes grupos sociais, culturais e étnicos.

\section{Conflitos, preconceito, discriminação e racismo no cotidiano escolar}

Professora, tá me chamando de cabelo duro.

Seu macaco!

Marcele sua macaca. Eu não sou macaca. Você é, sim, macaca, lá na favela todo mundo chama você de macaca.

Esses depoimentos apresentam como o espaço do cotidiano escolar é marcado por relações conflituosas entre as crianças e os adultos. Assim, foi possível observar que as crianças percebem e convivem com as diferenças. Ao chamar uma criança de "macaca, de bruxa e de cabelo duro," estão sendo demarcadas as diferenças, mas um discurso e uma postura que reconheçam e valorizem positivamente as diferenças no cotidiano escolar exige da professora trabalhar estas questões não somente quando emergem de modo conflitivo, mas reconhecendo e valorizando as diferenças no dia a dia da sala de aula.

$\mathrm{Na}$ escola onde foi desenvolvida a pesquisa duas professoras afirmaram que não existem diferenças, pois todos são iguais. Uma professora afirmou que tenta orientar as 


\section{RevistAleph}

crianças para respeitar a todos/as. Outra professora afirmou que na sala dela não deixa acontecer, mas essas práticas em relação ao preconceito e à discriminação são reais e acontecem na escola e em qualquer local da sociedade brasileira. Esta professora que afirmou que o preconceito é real, se autodeclarou negra e foi a única professora que já participou de cursos sobre questões da diversidade na escola e na sociedade quando era aluna do Curso Pedagogia na Universidade Federal Fluminense. A diretora adjunta afirmou na entrevista que essas práticas sempre acontecem, mas que é sempre negro contra negro porque na escola a grande maioria é negra:

De vez em quando acontecem alguns conflitos, mas é muito de vez em quando. Mas quando tem a gente percebe que é negro contra negro. São eles mesmos que discriminam, pois na escola a grande maioria é negra. [...] O último caso recente que aconteceu aqui na escola foi um menino negro que veio reclamar que uma menina disse para ele: "Eu não quero ficar perto desse menino preto" $E$ aí procuramos saber do caso, para conversamos. Mas aí a menina era da mesma cor dele, então os conflitos aqui são eles próprios, negros com negros. A menina era negra também (Diretora Adjunta da Escola).

De acordo com as Diretrizes Curriculares Nacionais para a Educação das Relações Étnico-raciais e para a o Ensino e Cultura Afro-brasileira e Africana (2004) é um grande equívoco esta afirmação de que negros se discriminam entre si e que são racistas também. Pois esta afirmação tem de ser analisada de acordo com a construção da ideologia do branqueamento que divulga a ideia de que as pessoas brancas seriam mais humanas, mais inteligentes e superiores, e, por isso, seriam mais capazes de comandar e dizer o que é bom para todos.

\section{Considerações finais}

A educação é reconhecida como um dos fundamentos sobre os quais se assenta o desenvolvimento político, social e econômico das sociedades. Contudo, as desigualdades sociais e regionais, a pobreza acentuada, enorme concentração de renda, 


\section{RevistAleph}

as discriminações de raça, gênero e idade, a baixa qualidade do ensino público, entre outros problemas, ainda estão presentes na realidade brasileira.

Sendo assim, podemos afirmar que a temática da diversidade étnica e racial tem muito a contribuir para a construção de práticas emancipatórias, em busca de uma educação democrática, que respeite e aborde as diferenças étnicas, culturais e sociais ajudando na construção da identidade das crianças negras no contexto da escola e da sociedade. O multiculturalismo e a perspectiva intercultural têm muito a oferecer para este contexto tão desigual que ainda sobrevive com práticas que excluem, selecionam e hierarquizam.

Mas, segundo Candau (2008) há que se desconstruir as práticas naturalizadas e enraizadas no trabalho docente para sermos educadores/as capazes de criar novas maneiras de situar-nos e intervir no dia a dia de nossas escolas e salas de aula.

Assim, faz-se necessário afirmar que a formação de profissionais para a diversidade étnica e racial no contexto escolar é de fundamental importância para uma prática compromissada com a inclusão, a valorização da diversidade racial e a luta para a construção de uma sociedade democrática, que garanta a todos/as o direito de uma educação cidadã, com práticas concretas que não discriminem nem excluam nenhum grupo social, étnico e religioso, principalmente dentre os que apresentam um histórico de exclusão e discriminação, como o povo negro na sociedade brasileira.

Os relatos abordados neste artigo demonstram que as professoras reconhecem as situações da diferença no contexto da escola, mas ao mesmo tempo, ainda não sabem lidar com esta situação, e acabam focando a questão no social. Ou seja, os problemas relacionados às questões de raça na escola, são reduzidos aos problemas sociais.

Os fatores sociais apontados pelas professoras para identificar os conflitos existentes entre alunos/as demonstram que as mesmas têm dificuldade de assumir as tensões étnico-raciais presentes no ambiente escolar. Deste modo, acabam 


\section{RevistAleph}

contribuindo para a permanência de manifestações preconceituosas no cotidiano escolar entre os diferentes alunos/as e adultos/as.

A pesquisa realizada oferece indícios e pistas para a construção de uma educação pautada na perspectiva intercultural e em sintonia com os estudos sobre as relações raciais que possa contribuir ativamente para o enfrentamento da desigualdade e da discriminação racial, tendo como meta a igualdade no respeito às diferenças no cotidiano escolar. Através das histórias de vida, da referência à diversidade de religiões, das músicas cantadas pelas crianças, das brincadeiras, das falas sobre suas comunidades, as crianças demonstram interesses e emitem opiniões sobre os acontecimentos do cotidiano da cidade, da favela e de suas famílias. Estas referências não são, em geral, levadas em consideração no dia a dia da sala de aula e do desenvolvimento curricular. No entanto, na perspectiva intercultural, oferecem inúmeros temas a serem explorados e trabalhados, em que o reconhecimento e a valorização das diferenças se façam presentes, assim como o diálogo entre saberes sociais e saberes curriculares. A escola, neste contexto, tem possibilidades de criar estratégias para que a sala de aula se torne um local de socialização e de múltiplas narrativas (MCLAREN, 2000), de transformação e principalmente que promova o empoderamento dos diferentes grupos sociais que dela fazem parte.

Ressalto também a importância da educação intercultural para o atual contexto educacional e para a promoção de uma educação pautada nas relações multiculturais, com o objetivo de garantir uma educação de iguais direitos para o pleno desenvolvimento de todos e de cada um enquanto pessoa, cidadão, principalmente das crianças.

No entanto, acredito que sua introdução nos processos de formação inicial e continuada de professores poderá contribuir para a construção de práticas democráticas, plurais e emancipatórias e estimular que a escola desenvolva estratégias para a valorização das crianças negras como sujeitos de direitos, cidadãs, produtoras e 


\section{RevistAleph}

construtoras de conhecimentos. Assim, destaco a importância da formação de professores para a promoção de uma educação multi e intercultural em nossas escolas.

Como já afirmei, esta pesquisa buscou compreender como a escola vivencia as relações étnicorraciais no cotidiano escolar a partir das "vozes" das professoras sobre as crianças negras no cotidiano da escola pesquisada e será dedicado à análise sobre sua realidade e suas relações no ambiente escolar. Através deste olhar, na simplicidade das vozes e dos olhares de cada criança, fui aprendendo a ver e a tecer um texto com a melodia e as diferenças que elas explicitavam.

\section{Referências}

BRASIL, Diretrizes Curriculares Nacionais para a Educação das Relações Raciais Étnico-Raciais e para o Ensino de História e Cultura Afro-Brasileira e Africana. Brasília: MEC, 2004.

CANDAU, Vera Maria e MOREIRA, Antonio Flávio (Orgs.). Multiculturalismo e educação: desafio para prática pedagógica. In: Multiculturalismo diferenças culturais e práticas pedagógicas. Petrópolis, RJ: Vozes, 2008.

CANDAU, Vera e Koff, Adélia Maria Neme Simão. Conversas com. Sobre a Didática E A Apresentação Multi/Intercultural. Revista Educação \& Sociedade. Campinas Vol. 27, n.95, p. 471-493, maio/ago. 2006.

CANDAU, Vera Maria. Educação intercultural e cotidiano escolar (Org.). Rio de Janeiro: 7 Letras, 2006.

CANDAU, Vera Maria (Org.) Sociedade, educação e cultura(s): questões e propostas. Petrópolis, RJ. Vozes, 2002.

CANDAU, Vera Maria (Orgs.). Cultura (s) e educação: Entre o crítico e o pós - crítico. Rio de janeiro, DP \& A, 2005.

CARVALHO, Marília Pinto de. Por que tantos meninos vão mal na escola? Critérios de avaliação escolar segundo o sexo. 30a reunião anual da Anped, 2007, GT 14. Disponível em < www.anped.org.br>.

CARVALHO, Marília Pinto de. Quem são os meninos que fracassam na escola? Cadernos de Pesquisa, v.34, n.121, p.11-40, jan./abr. 2004. 


\section{RevistAleph}

CAVALLEIRO, Eliane dos Santos. Do silêncio do lar ao silêncio escolar: racismo e preconceito e discriminação na educação infantil. São Paulo: Contexto, 2a edição, 2003.

DUARTE, Rosália. Entrevistas em pesquisas qualitativas. Rio de Janeiro. Mimeo. Publicada em Educar em Revista, Curitiba, v. 24, p. 213-226, 2004.

FLEURY, Reinaldo Matias. Intercultura, educação e movimentos sociais: A perspectiva de pesquisas desenvolvidas pelo núcleo mover. In: LOPES. M, A. RC, MACEDO, E. F. e ALVES, M. P. C. (Orgs.) Cultura e política de currículo. São Paulo: Junqueira Marin, 2006.

FLEURY, Reinaldo Matias. Intercultura e Educação. Revista Brasileira de Educação.

Maio/jun/julho, 2003, n. 23.

FLEURY, Reinaldo Matias. Políticas da diferença: para além dos estereótipos na prática educacional. Educação e Sociedade, Campinas, v. 27, n.95, p. 495-520, maio/ago. 2006. FLEURY, Reinaldo Matias. Intercultura e Educação. Revista Brasileira de Educação. Maio/jun/jul/ago, 2003, n. 23.

FLEURY, Reinaldo Matias e AZIBEIRO, N. Esperança. Paradigmas interculturais emergentes na educação popular. In: II Congresso Internacional: Cotidiano - Diálogos sobre diálogos. Realização Grupalfa. Universidade Federal Fluminense, Niterói, 2008.

FORQUIN, Jean-Claude. Escola e cultura:as bases sociais e epistemológicas do conhecimento escolar. Porto Alegre: Artes Médicas, 1993.

HANSEBALG, Carlos. Discriminação e desigualdades raciais no Brasil. Belo Horizonte: Editora UFMG; Rio de Janeiro: IUPERJ, 2a Edição, 2005.

ANDRÉ, Marly. Etnografia da prática escolar. São Paulo: Papirus, 2006.

MCLAREN, Peter. Multiculturalismo crítico. São Paulo: Cortez, 2000.

MCLAREN, Peter. A vida nas escolas: uma introdução à pedagogia crítica nos fundamentos da educação. Porto Alegre: Artes Médicas, 1997.

MCLAREN, Peter. Pela abolição da brancura. (entrevista) Revista espaço acadêmico- n.32 Jan. 2004 .

SARMENTO, Manuel Jacinto. 0 estudo de caso etnográfico em educação. In: ZAGO, Nadir, CARVALHO, Marilia Pinto de, VILELA, Rita Amélia Teixeira (orgs). Itinerários da pesquisa: perspectivas qualitativas em sociologia da educação. Rio de Janeiro: DPYA, 2003.

Data do envio: $16 / 09 / 2020$

Data do aceite: $14 / 04 / 2021$ 